Check for updates

Cite this: J. Anal. At. Spectrom., 2017 32,1766

Received 24th March 2017

Accepted 12th June 2017

DOI: 10.1039/c7ja00107j

rsc.li/jaas

\title{
Potential of the hydride generation technique coupled to inductively coupled plasma optical emission spectrometry for non-chromatographic As speciation
}

\author{
Maja Welna * * and Pawel Pohl
}

A systematic study of hydride generation $(\mathrm{HG})$ in the sample introduction step combined with inductively coupled plasma optical emission spectrometry (ICP OES) for non-chromatographic As speciation from solutions of $\mathrm{As}(\mathrm{II}), \mathrm{As}(\mathrm{V})$, dimethylarsinate (DMA) and monomethylarsonate (MMA) is presented. Hydrides were generated in the reaction with $\mathrm{NaBH}_{4}$ in the acidic medium using a continuous flow system with a gas-liquid phase separation directly coupled with ICP. Optimization of the HG operational parameters was performed to improve the detectability of As. The different reactivities of the examined As species under various reaction conditions [in terms of the type and concentration of acids $(\mathrm{HCl}$, acetic and citric), buffers (acetate and citrate), the $\mathrm{NaBH}_{4}$ concentration and presence of pre-reducing agents (KIascorbic acid, thiourea-ascorbic acid and L-cysteine)] were used for selective generation of their individual hydrides. The relationship among As(III), As(v), DMA and MMA signals under different reduction conditions was studied and discussed. Considering all favorable pre-reducing and HG reaction conditions, five speciation procedures (SPS) for species-selective HG of As in one solution, including SP1 for $[$ As(III)], SP2 for $[A s(I I)+D M A], S P 3$ for $[A s(I I)+A s(V)+M M A]$, SP4 for [DMA + MMA] and SP5 for [As(III) $+\operatorname{As}(v)+D M A+M M A]$, were evaluated. Differentiation between As(III), As(v), DMA and MMA along with distinguishing between species having the same nature, i.e. i-As [As(II,v)] and o-As (DMA, MMA), was achieved. By combining the analytical responses obtained with HG-ICP OES, the experimental protocols for determination and non-chromatographic speciation (both individual and operational) of hydrideactive As species were proposed.
\end{abstract}

\section{Introduction}

Arsenic may exist in various chemical forms, having different toxicities ranging from highly hazardous inorganic arsenicals (iAs), i.e. arsenite $[\mathrm{As}(\mathrm{III})]$ and arsenate $[\mathrm{As}(\mathrm{v})]$, to relatively harmless organic forms (o-As), i.e. monomethylarsonate (MMA) and dimethylarsinate (DMA). Other o-As compounds, e.g. arsenobetaine (AsB), are non-toxic to humans. ${ }^{1}$ Since the toxicity of As is species dependent, today, determination of the total As content is insufficient and speciation information is mandatory to reflect the risk associated with exposure to As.

In the traditional approach, the most popular strategy for speciation of toxic As forms is based on their chromatographic separation and detection using spectrometric detectors, i.e. inductively coupled plasma mass spectrometry (ICP MS), ICP optical emission spectrometry (ICP OES), atomic absorption spectrometry (AAS) or atomic fluorescence spectrometry (AFS),

Wroclaw University of Technology, Faculty of Chemistry, Division of Analytical Chemistry and Chemical Metallurgy, Wybrzeze Wyspianskiego 27, 50-370 Wroclaw, Poland.E-mail: maja.welnal@pwr.edu.pl however, HPLC-ICP MS is favored due to the low detection limits (DLs) of the As species and their high selectivity. ${ }^{\text {e.g. }}{ }^{2-4}$ Otherwise, the current interest in speciation analysis of As goes into development of robust and reliable non-chromatographic methods. These methods are based on the selective solvent extraction of i-As followed by its direct measurement using spectrometric techniques, including ICP-MS, ${ }^{\mathbf{5 , 6}}$ graphitefurnace (GF) AAS, ${ }^{7,8}$ and electrospray ion-trap MS. ${ }^{9}$ They also include extraction of all As species followed by separation of i-As from o-As using different chemical methods and detection with AFS, AAS or ICP MS. ${ }^{\mathbf{1 0 - 1 4}}$ Commonly, a separation step involves anion-exchange (AE) solid-phase extraction (SPE), ${ }^{\mathbf{1 0 - 1 2}}$ enabling selective retention of $\mathrm{i}$-As or by derivatization through hydride generation (HG) under specific reductive conditions. ${ }^{13,14}$

Among the aforementioned methods, HG is one of the most straightforward approaches and the recommended way for determination of trace amounts of the total As concentrations. ${ }^{15}$ It is applied in hyphenation with atomic spectroscopy to the elements that form volatile species in the reaction with sodium tetrahydroborate $\left(\mathrm{NaBH}_{4}\right)$ in acidic media (usually $\left.\mathrm{HCl}\right){ }^{16}$ Application of $\mathrm{HG}$ in the sample introduction step can satisfy 
the selectivity and detectability requirements to a large extent. ${ }^{15,17,18}$ Satisfactorily, all major toxic As compounds, i.e. iAs $[\mathrm{As}(\mathrm{III}, \mathrm{V})]$ and o-As (DMA, MMA), are hydride-active and react with $\mathrm{NaBH}_{4}$, forming the corresponding hydrides, i.e. $\mathrm{AsH}_{3},\left(\mathrm{CH}_{3}\right)_{2} \mathrm{AsH}$ and $\mathrm{CH}_{3} \mathrm{AsH}_{2}$ for As(III,v), DMA and MMA, respectively. ${ }^{19,20}$ Unfortunately, the effectiveness of the HG processes of these individual As forms depends on the experimental conditions used and largely differs. Generally, different As species do not generate hydrides with similar efficiency, hence determination of total As (t-As) by HG in all these species can be problematic. ${ }^{20}$ A pre-reduction step is usually carried out as HG is sensitive only when the As species are present in their lower oxidation states. However, when As(III) and As(v) species similarly respond under appropriately selected reaction conditions, previous pre-treatment before HG can be avoided. ${ }^{21-23}$

On the other hand, by using species-selective HG, speciation of As is possible. Non-chromatographic approaches to differentiation of the four As species, being the direct benefit of HG, are less time-consuming, simpler and more cost-effective alternatives to speciation of As carried out by HPLC. ${ }^{13,24,25}$ Selectivity is based on (1) differences in the reaction rate of the As species with $\mathrm{NaBH}_{4}$ in the $\mathrm{HCl}$ medium, (2) the aciditydependent reduction reaction between the As species and $\mathrm{NaBH}_{4}$, critically affected by the type and concentration of acid or buffer used as well as $\mathrm{pH}$ of the reacting medium and (3) absence or presence of additives, including pre-reductants or chelating/masking reagents. Accordingly, the individual hydrides can be generated either selectively under different chemical conditions or together with other species in various reaction media. As a result, based on the different responses of the four As species resulting from HG, experimental protocols for As speciation are proposed. .6-32 $^{2}$

There is no doubt that the procedures of speciation of all four As forms by means of $\mathrm{HG}$ are the most desired but also the most demanding and challenging because their development has to be proceeded by careful optimization of the experimental parameters, being appropriate for each As species present in the sample solution. Hence, most of the studies dealing with nonchromatographic As speciation by $\mathrm{HG}$ focus on i-As, and concern discrimination between $\mathrm{As}(\mathrm{III})$ and As(v) only. ${ }^{21-23,33-42}$ In contrast, the role of o-As is rather diminished. Contribution of o-As to the quantified concentration of i-As or As(III) can only be assessed by evaluating the interferences of DMA and MMA on the As signal under the selected HG reaction conditions. ${ }^{\mathbf{1 3 , 1 4 , 3 8 , 4 1}}$ Importantly, results show that the presence of DMA and MMA may influence the analytical response of As, therefore, the developed method, although accurate for i-As, can be applied to the samples with no or negligible amounts of the methylated As forms..$^{13,38,41}$ It must be commented that even though i-As is the dominant As species in most samples, other As species present in them cannot be ignored and the behavior of all hydride-active As species during $\mathrm{HG}$ should be verified to obtain reliable results. ${ }^{14}$ Optionally, to overcome the interfering effect of DMA and MMA on the determination of i-As, SPE with specific sorbents, i.e. silica-based, strong anion-exchange (SAX) cartridges, ${ }^{\mathbf{1 0 - 1 2}}$ can be used to separate i-As from o-As before HG.
Determination and speciation of As by HG from the sample solutions containing various inorganic and organic species of this element is not an easy task because several factors affecting HG efficiency have to be carefully controlled and taken into account to improve the accuracy of the analysis. In reference to this, the objective of this work was to investigate the analytical proceeding for As speciation by a non-chromatographic approach based on $\mathrm{HG}$ and differentiation of certain toxicologically relevant As species, i.e. As(III), As(v), DMA and MMA. Different reactivities of the As species under various reaction conditions were used for selective generation of the individual hydrides and evaluation of the relationships among the As signals. Possibilities of erroneous interpretations of the results are also pointed out. Analytical procedures for species-selective discrimination and determination of As(III), As(v), DMA and MMA were optimized, based on the different responses of the As species toward HG. Both speciation and fractionation schemes along with the procedures for total As determination are proposed. It is worth noting that such non-chromatographic As analysis and speciation by HG-ICP OES, as far as we know, has not been presented yet.

\section{Experimental}

\subsection{Reagents and solutions}

All chemicals were of analytical grade. Stock standard solutions of As(III), DMA and MMA (1000 $\left.\mu \mathrm{g} \mathrm{mL}^{-1}\right)$ were obtained from their respective salts, i.e. sodium metaarsenite $\left(\mathrm{NaAsO}_{2}\right)$, sodium cacodylate $\left(\mathrm{C}_{2} \mathrm{H}_{6} \mathrm{AsNaO}_{2} \times 3 \mathrm{H}_{2} \mathrm{O}\right)$ and disodium methyl arsenate $\left(\mathrm{CH}_{3} \mathrm{AsNa}_{2} \mathrm{O}_{3}\right)$, all of them from Sigma-Aldrich (St Louis, MO, USA). These As species stock solutions were prepared on a mass basis and then stored at $4{ }^{\circ} \mathrm{C}$ without adding any preservatives. In the case of As(v), a Merck (1000 $\mu \mathrm{g}$ $\mathrm{mL}^{-1}$ ) ICP standard solution (Merck, Darmstadt, KGaA, Germany) was used. Single and mixed working solutions were obtained by serial dilutions of the stock standards with water. Synthetic sample solutions of the As species were freshly prepared and analyzed in all the experiments. Single standard solutions (20 ng $\mathrm{g}^{-1}$ as As) for each As species, made either in water only, acidified with different acid media or prepared in the presence of various pre-reducing agents, were investigated.

To acidify the sample solutions and/or to use the additional acid solutions in the $\mathrm{HG}$ reaction, 37\% (m/v) $\mathrm{HCl}$ (SigmaAldrich) and $80 \%(\mathrm{~m} / \mathrm{v}) \mathrm{CH}_{3} \mathrm{COOH}$ solutions (Avantor Performance Reagents, Gliwice, Poland) and a $2 \mathrm{~mol} \mathrm{~L}^{-1}$ citric acid solution, made by dissolution of solid $\mathrm{C}_{6} \mathrm{H}_{8} \mathrm{O}_{7} \times \mathrm{H}_{2} \mathrm{O}$ powder (Avantor Performance Reagents), were applied. Depending on the $\mathrm{HG}$ reaction conditions, the sample solutions were acidified to $3 \mathrm{~mol} \mathrm{~L}^{-1}$ with $\mathrm{HCl}$, while 0.01 to $10 \mathrm{~mol} \mathrm{~L}^{-1}(\mathrm{HCl}), 0.01$ to $4 \mathrm{~mol} \mathrm{~L}^{-1}\left(\mathrm{CH}_{3} \mathrm{COOH}\right)$ and 0.01 to $2 \mathrm{~mol} \mathrm{~L}^{-1}\left(\mathrm{C}_{6} \mathrm{H}_{8} \mathrm{O}_{7}\right)$ solutions of acids were additionally employed for the $\mathrm{HG}$ reaction.

Solutions of $\mathrm{CH}_{3} \mathrm{COOH}$ and $\mathrm{C}_{6} \mathrm{H}_{8} \mathrm{O}_{7}$ at adjusted $\mathrm{pH}$ (buffers) were prepared and used as diluents of the sample solutions to test the effect of $\mathrm{pH}$ on HG for the different As forms. For this purpose, $0.2,0.5$ and $1.0 \mathrm{~mol} \mathrm{~L}^{-1}$ acetic acid/sodium acetate buffers $(\mathrm{pH}=4.5)$ were prepared by mixing appropriate aliquots of $\mathrm{CH}_{3} \mathrm{COOH}$ and $\mathrm{CH}_{3} \mathrm{COONa}$ solutions, while $0.1 \mathrm{~mol} \mathrm{~L}^{-1}$ citric 
acid/sodium citrate buffer $(\mathrm{pH}=5.2)$ was prepared from $\mathrm{C}_{6} \mathrm{H}_{8} \mathrm{O}_{7}$ and $\mathrm{C}_{6} \mathrm{H}_{5} \mathrm{Na}_{3} \mathrm{O}_{7}$ solutions. $\mathrm{pH}$ was measured with a $\mathrm{pH}$ meter (type CP-401, Elmetron, Poland) with a glass electrode at $25{ }^{\circ} \mathrm{C}$.

L(+)-Ascorbic acid (AA, Avantor Performance Reagents), Lcysteine (LC, Sigma-Aldrich), KI (Avantor Performance Reagents) and thiourea (TU, Sigma-Aldrich) were used as the pre-reducing agents. Their single solutions, i.e. 4.0 or $10 \%(\mathrm{~m} / \mathrm{v})$ $\mathrm{AA}, \mathrm{LC}, \mathrm{KI}$ and TU, in addition to the mixed solutions, i.e. KI $(2.0 \%)-\mathrm{AA}(8.0 \%)$ and TU (4.0\%)-AA (4.0\%), were prepared by dissolving the respective solid reagents in water. In the case of pre-reduction with $\mathrm{AA}, \mathrm{KI}$ and $\mathrm{TU}$, the sample solutions were treated with KI and TU (individually) or with their mixtures with AA before final acidification to the optimum $\mathrm{HCl}$ concentration, i.e. $3 \mathrm{~mol} \mathrm{~L}^{-1}$. In contrast, the sample solutions treated with LC were not acidified at all, i.e. they were prepared only in pure water.

A $1.0 \%(\mathrm{~m} / \mathrm{v}) \mathrm{NaBH}_{4}$ (Sigma-Aldrich) solution was used for the HG reaction. It was prepared daily by dissolving an appropriate amount of powdered $\mathrm{NaBH}_{4}$ in a $0.1 \%(\mathrm{~m} / \mathrm{v}) \mathrm{NaOH}$ (Sigma-Aldrich) solution for stabilization, and filtered $(0.45 \mu \mathrm{m})$ before being used to eliminate turbidity. For investigation of the effect of the $\mathrm{NaBH}_{4}$ concentration on the As response, solutions of $\mathrm{NaBH}_{4}$ at the concentration ranging from 0.01 to $1.0 \%$ were made. Importantly, the $\mathrm{NaOH}$ concentration [in \% (m/v)] used to stabilize $\mathrm{NaBH}_{4}$ was always kept 10 times less than the concentration of the reductant.

De-ionized water $(18.3 \mathrm{M} \Omega \cdot \mathrm{cm})$ from an EASYpure system (Barnstead, Model D7033) was used in all the experiments.

\subsection{Sample pre-treatment with pre-reducing agents (pre- reduction of As species)}

For pre-reduction with KI alone or its mixture with AA (KI-AA) as well as TU alone or its mixture with AA (TU-AA), appropriate aliquots of the concentrated pre-reducing agent solutions were placed in PP capped containers, into which appropriate aliquots of the As(v), DMA or MMA working standard solutions were added. Final concentrations of the pre-reducing agents were: $0.5 \%(\mathrm{KI})$ and $1.0 \%$ (TU) (individually) or $0.5-2.0 \%$ and 1.0 $1.0 \%$ (mixtures of $\mathrm{KI}$ and TU with $\mathrm{AA}$, respectively). These solutions were mixed, completed with a $4 \mathrm{~mol} \mathrm{~L}^{-1} \mathrm{HCl}$ solution to ensure required acidity $\left(3 \mathrm{~mol} \mathrm{~L}^{-1}\right)$, and finally left to react before the measurements by HG-ICP OES. For combination of $\mathrm{KI}-\mathrm{AA}$ and TU-AA, the influence of the pre-reducing agents added individually before acidification, i.e. at first AA and then KI or TU (AA + KI or AA + TU), or already mixed (KI-AA or TU-AA) on the performance of the pre-reduction reaction of the different As species was checked. In the procedure with LC, to the appropriate aliquot of this concentrated pre-reducing agent solution, appropriate aliquots of the As(v), DMA or MMA single standard solutions were added and completed with water to reach the final LC concentration in the resulting solutions equal to $0.5 \%$, and left to react prior to analysis. All these experiments were performed at room temperature and a contact time of 30 min was sufficient for pre-reduction of all the As species. To properly assess the effects of the pre-reducing agents on HG of
As and obtain reliable As responses, the As(III) standard solution was also treated with all the studied pre-reducing agents used for pre-reduction. The respective blank sample solutions were always prepared in the same way as the standard solutions and considered in the final results.

\subsection{Arsenic hydride generation and measurements}

The corresponding arsenic hydrides (arsines) from the four As species were generated using a continuous flow system with gas-liquid phase separation directly combined with the ICP OES spectrometer. The system consisted of a modified cyclonic spray chamber (that acts only as a phase separator), a parallel Burgener-type pneumatic nebulizer, Y-shaped (Y) connectors, a reaction coil and peristaltic pumps with delivery tubes. ${ }^{43}$

In the manifold used, reagents, i.e. sample (S), additional acid (A) and $\mathrm{NaBH}_{4}$ (R) solutions, were simultaneously pumped in separate streams using two peristaltic pumps. Two combinations were used, i.e. with three (1) and two (2) streams of the reagents. In the (1) approach, the $\mathrm{S}$ and A solutions were merged in the first $\mathrm{Y}$ connector, then the resulting acidified sample solution was delivered to the second Y connector, where it was mixed with the incoming $\mathrm{R}$ solution. The resulting heterogeneous reaction mixture was introduced through the reaction coil (PTFE tubing $5 \mathrm{~cm} \times 0.5 \mathrm{~mm}$ i.d.) to a special cavity at the bottom of the chamber (i.e. the U-shaped end part of the chamber) to separate the volatile species from the liquid phase. Arsines and other gaseous co-products were swept by a carrier Ar stream, introduced through the gas inlet of the nebulizer mounted onto the cyclonic spray chamber, and immediately transported to the plasma torch. The sample inlet of the nebulizer was clogged. The post-reaction waste solution was drained from the chamber with the aid of the third peristaltic pump. Employing the (2) combination, a stream of the A solution was excluded, hence only one $\mathrm{Y}$ connector was necessary. In this manifold, the already acidified S solution and the R solution were mixed in the $\mathrm{Y}$ connector, followed by introduction of the resulting reaction mixture (through the reaction coil) to the U-type end part of the chamber.

All measurements were performed with the use of the Jobin Yvon (France) sequential optical emission, radially viewed ArICP spectrometer, model JY 38S. The operating parameters for the HG reaction and ICP OES detection are listed in Table 1. A sequential mode to record the analytical line profiles was applied. The background corrected net intensities $\left(I_{\text {net }}\right)$ of the analytical line of As (mean of three repeated measurements, $n=$ 3) were used for the studies.

\section{Results and discussion}

To investigate the suitability of HG-ICP OES for As speciation, the signals (the background corrected net intensities of the As I emission line) acquired for the As(III), As(v), DMA and MMA single-species standard solutions were monitored under various HG reaction conditions related to the combined $\mathrm{NaBH}_{4}-$ acid system. The effect of the oxidation state and the nature of the examined As species on the performance of their reaction with 
Table 1 Optimized operating conditions for the HG-ICP OES measurements of As

$\begin{array}{ll}\text { ICP OES spectrometer (detection) } & 40.68 \\ \text { Generator }(\mathrm{MHz}) & 1000 \\ \text { RF power }(\mathrm{W}) & 2.5 \\ \text { Injector i.d. }(\mathrm{mm}) & \text { Radial: } 12 \text { mm above the load coil } \\ \text { Observation zone } & \text { Plasma: } 13.0 \\ \text { Ar flow rate }\left(\mathrm{L} \mathrm{min}^{-1}\right) & \text { Auxiliary: } 0.2 \\ & \text { Nebulizer gas: } 0.35 \\ \text { Integration time (s) } & 0.10 \\ \text { Measurement replicate } & 3 \\ \text { Analytical line wavelengths }(\mathrm{nm}) & \text { As I }^{a} 193.7\end{array}$

Continuous flow hydride generation (CF-HG) with gas-liquid phase separation Solution flow rate $\left(\mathrm{mL} \mathrm{min}{ }^{-1}\right)$

Reagent concentrations ${ }^{b}$

Reductant solution (R): $\mathrm{NaBH}_{4}[\%(\mathrm{~m} / \mathrm{v})]$

Sample solution (S):

Aqueous

Acidic (sample acid concentration)
Sample (S): 1.5

Additional acid (A): 1.0

Reductant (R): 1.0

0.1 or 1.0 (in 0.01 or $0.1 \%(\mathrm{~m} / \mathrm{v}) \mathrm{NaOH})$

Not acidified

$3 \mathrm{~mol} \mathrm{~L}^{-1} \mathrm{HCl}$

$0.2 \mathrm{~mol} \mathrm{~L}^{-1} \mathrm{CH}_{3} \mathrm{COOH}$

$\mathrm{pH}=4.5$ (acetic/acetate buffer)

$\mathrm{pH}=5.2$ (citric/citrate buffer)

2 or $10 \mathrm{HCl} \mathrm{mol} \mathrm{L}{ }^{-1}$

$0.5 \mathrm{~mol} \mathrm{~L}^{-1} \mathrm{CH}_{3} \mathrm{COOH}$

$0.5 \%(\mathrm{KI})-2.0 \%(\mathrm{AA})$

$0.5 \% \mathrm{LC}$

${ }^{a}$ I: atomic line. ${ }^{b}$ The concentration of the reagent in the final sample solution depending on the HG reaction and pre-reduction conditions used.

$\mathrm{NaBH}_{4}$ was scrupulously examined by generating the hydrides in the presence and absence of different pre-reducing agents. The optimized $\mathrm{HG}$ reaction and pre-reduction conditions, providing selective generation of the As hydrides from different As species by HG-ICP OES, were proposed.

\subsection{Optimization of the HG-ICP OES variables}

Initial optimization studies were carried out to achieve the best performance of the HG-ICP OES system in terms of sensitivity and accuracy of the measurements of the As signals. The ICP instrumental parameters summarized in Table 1, e.g. the RF power and the Ar flow rates, were set according to the recommendations given by its manufacturer. The most sensitive As atomic emission line at $193.7 \mathrm{~nm}$ was selected for the study using conventional PN sample introduction. The criterion for its selection from among other As emission lines, i.e. $197.3 \mathrm{~nm}$, $228.8 \mathrm{~nm}$ and $234.9 \mathrm{~nm}$, was the maximum signal-tobackground (SBR) ratio.

In the case of the $\mathrm{HG}$ reaction, typical reductant-acid conditions, i.e. $\mathrm{NaBH}_{4}$ combined with $\mathrm{HCl}$, were used. $\mathrm{NaBH}_{4}$ and $\mathrm{HCl}$ concentrations were kept at $1.0 \%(\mathrm{~m} / \mathrm{v})$ and $3 \mathrm{~mol} \mathrm{~L}^{-1}$, respectively. ${ }^{17}$ The $\mathrm{S}$ solution contained $20 \mathrm{ng} \mathrm{g}^{-1}$ of $\mathrm{As}(\mathrm{III})$ and was acidified with $\mathrm{HCl}$. The corresponding As hydride $\left(\mathrm{AsH}_{3}\right)$ was generated by merging the $\mathrm{S}$ and $\mathrm{R}$ solutions. Otherwise, the A solution with $\mathrm{HCl}$ was merged at first with the S solution, and the resulting acidified solution was next merged with the $\mathrm{R}$ solution. Acidity referring to $3 \mathrm{~mol} \mathrm{~L}^{-1} \mathrm{HCl}$ in the $\mathrm{S}$ solution after mixing with the A solution was chosen to keep the constant
$\mathrm{HCl}$ concentration available for the reaction with $\mathrm{NaBH}_{4}$, regardless of the manifold applied to $\mathrm{AsH}_{3}$ generation. Accordingly, two different $\mathrm{HG}$ reaction conditions were used, i.e. 0 (S)-6 (A) $\mathrm{mol} \mathrm{L}^{-1} \mathrm{HCl}$ or $3(\mathrm{~S})-3(\mathrm{~A}) \mathrm{mol} \mathrm{L}^{-1} \mathrm{HCl}$, while the $\mathrm{NaBH}_{4}$ concentration was the same (1.0\%). Optimization was based on a one-factor-at-a-time (OFAT) approach, by changing one parameter, while keeping the others constant. It included: (1) the reagents, i.e. S, A and R solution flow rates $(0.5-1.5 \mathrm{~mL}$ $\mathrm{min}^{-1}$ ); (2) the speed of the waste removal from the chamber (regulated by the speed of the peristaltic pump); (3) the reaction coil length $(5-25 \mathrm{~cm})$ as well as (4) the sample read delay time (DT), i.e. the time necessary to complete the HG reaction and obtain a consistent response for As before the measurement run (15-60 s). Briefly, it was found that the $\mathrm{S}$ and $\mathrm{R}$ solution flow rates were critical. Accordingly, the As response increased linearly with the increasing $\mathrm{S}$ solution flow rate. The highest

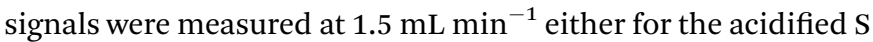
or the $\mathrm{S}$ solution initially mixed with the A solution. Similarly, an increase in the $\mathrm{R}$ solution flow rate led to a constant growth in the As response; however, above $1.0 \mathrm{~mL} \mathrm{~min}^{-1}$, repeatability of the As signals became poorer (RSDs $>15 \%$ ), probably due to larger $\mathrm{H}_{2}$ production that made the plasma unstable. In the case of the A solution, it was concluded that its flow rate of $1.0 \mathrm{~mL}$ $\min ^{-1}$ was necessary to achieve the maximum and stable As signals. Importantly, at optimum flow rates of all the reagents,

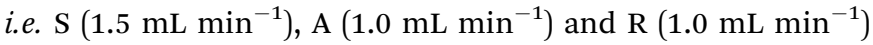
solutions, the As signals, acquired using for the reaction the acidified S solution or the S solution mixed with the A solution, 
were very close to each other. Considering the reaction coil length, the best results were obtained when the coil was the shortest. An increase in its length resulted in lower precision of the measured As signals (RSDs $>10 \%$ ). In addition, there was a higher risk of unsealing the system because of larger backpressure. The DT necessary to achieve the steady As response was $30 \mathrm{~s}$ after merging the acidified $\mathrm{S}$ and $\mathrm{R}$ solutions in the $\mathrm{Y}$ connector. Finally, the stability of the HG reaction conditions was assured by effective drainage of the out-coming liquid from the chamber. It was achieved when the level of the post-reaction solution in the U-type end part of the chamber was kept at a constant level. The flow rate of the waste solution was regulated by the speed of the peristaltic pump.

In consequence, the chosen optimal operating parameters (see Table 1) enabled us to achieve the highest As signals and signal to background ratios and satisfactory repeatability of measurements with HG-ICP OES; the detection limit $(3 \sigma)$ of 0.23 ng $\mathrm{g}^{-1}$ for $\mathrm{As}(\mathrm{III})$ was estimated using the standard solutions within 0 to $50 \mathrm{ng} \mathrm{g}^{-1}$, while the relative standard deviation (\% RSD) calculated for three repeated measurements of the background-corrected intensity of the As I emission line was better than $3 \%$.

\subsection{Arsine generation from various As species}

Next, the chemical $\mathrm{HG}$ reaction conditions affecting the formation of the As hydrides from As(III), As(v), DMA and MMA were examined to obtain the highest As response for speciesselective As detection by HG-ICP OES.

3.2.1 Effect of acidity. The effect of $\mathrm{HCl}$ and two organic acids, i.e. $\mathrm{CH}_{3} \mathrm{COOH}$ and $\mathrm{C}_{6} \mathrm{H}_{8} \mathrm{O}_{7}$, on arsine generation in the reaction with $1.0 \% \mathrm{NaBH}_{4}$ was studied. Preliminary, single standards of each As species prepared in water were used. The results are expressed as the $I_{\text {net }}$ (mean signals for $n=3$ repeated measurements) along with SDs and shown in Fig. 1 and 2 .

In the strong $\mathrm{HCl}$ media (Fig. 1a), all the As species were converted into their hydrides, but their responses depended on the $\mathrm{HCl}$ concentration. Maxima for DMA and MMA were reached at $0.25-0.5 \mathrm{~mol} \mathrm{~L}^{-1} \mathrm{HCl}$. Then, signals for DMA rapidly decreased to a negligible value in $10 \mathrm{~mol} \mathrm{~L}^{-1} \mathrm{HCl}$. The maximum As signal from MMA remained up to $4 \mathrm{~mol} \mathrm{~L}^{-1} \mathrm{HCl}$, with a slow decrease (up to $30 \%$ ) in more concentrated $\mathrm{HCl}$ solutions. The higher $\mathrm{HCl}$ concentration was suitable for i-As species. Their signals gradually increased to achieve constant values at $2[\mathrm{As}(\mathrm{III})]$ and $6[\mathrm{As}(\mathrm{v})] \mathrm{mol} \mathrm{L}^{-1} \mathrm{HCl}$. The results indicated that at a fixed $\mathrm{NaBH}_{4}$ concentration (1.0\%) and variable
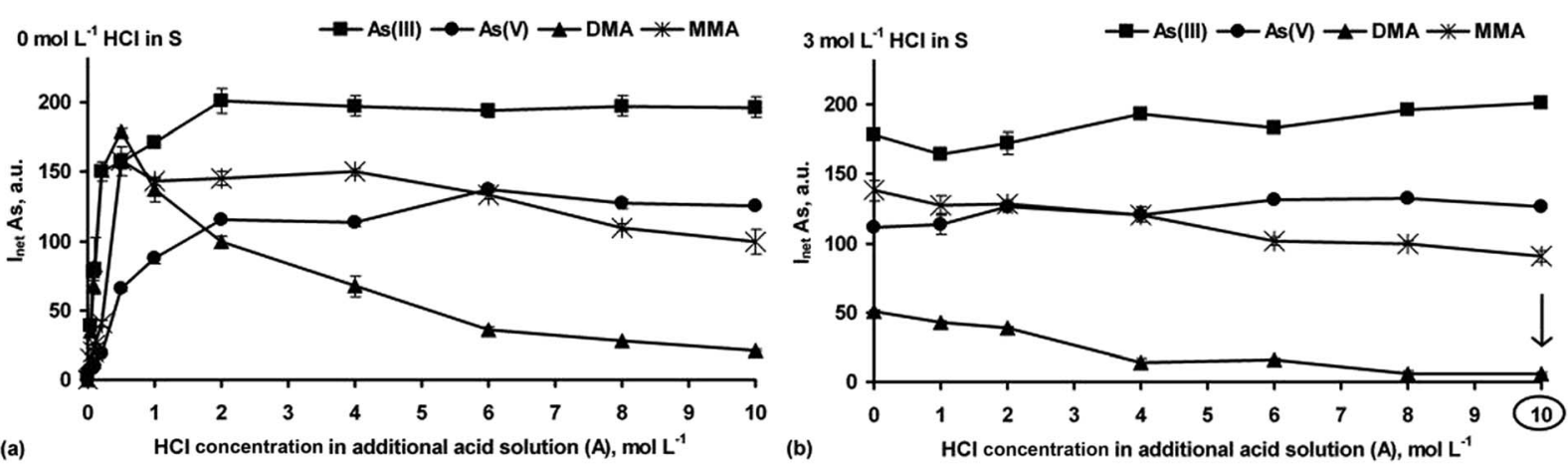

Fig. 1 Effect of acidity related to the $\mathrm{HCl}$ concentration in the additional acid (A) solution on the responses of As(III), As(V), DMA and MMA during arsine generation using a $1.0 \% \mathrm{NaBH}_{4}$ (R) solution. The simple $\mathrm{S}$ solutions of the As species (20 $\mathrm{ng} \mathrm{g}^{-1}$ each) were used (acidification with $\mathrm{HCl}$ was omitted) (a) or they were acidified with $\mathrm{HCl}$ to $3 \mathrm{~mol} \mathrm{~L}^{-1}$ (b).

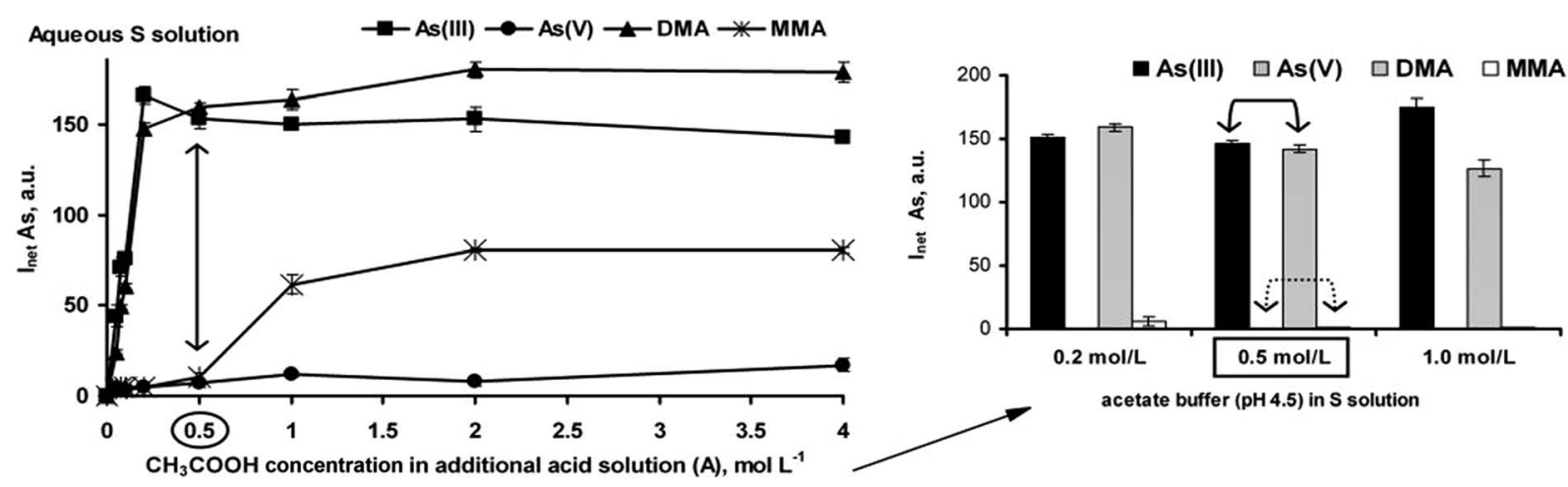

Fig. 2 Effect of acidity related to the $\mathrm{CH}_{3} \mathrm{COOH}$ concentration in the $\mathrm{S}$ and $\mathrm{A}$ solutions on the measurements of $\mathrm{As}(\mathrm{II}), \mathrm{As}(\mathrm{V})$, DMA and MMA (20 ng $\mathrm{g}^{-1}$ each) by HG-ICP OES using the $1.0 \% \mathrm{NaBH}_{4} \mathrm{R}$ solution. Left side: $\mathrm{CH}_{3} \mathrm{COOH}$ was used for the HG reaction. Simple $\mathrm{S}$ solutions (not acidified with $\mathrm{HCl}$ ) and the $\mathrm{A}$ solution containing $\mathrm{CH}_{3} \mathrm{COOH}$ at various concentrations were used. Right side: acetate buffer at adjusted pH was used for the HG reaction. The S solutions were acidified with the acetate buffer ( $\mathrm{pH} 4.5)$, the use of the A solution was excluded. 
$\mathrm{HCl}$ concentrations identical As responses for the studied As species could not be obtained. Such behavior agrees with previous reports. $^{20,26,27}$

The influence of $\mathrm{HCl}$ concentrations both in the $\mathrm{S}$ and $\mathrm{A}$ solutions on $\mathrm{HG}$ of the As species was also tested. A series of $\mathrm{S}$ solutions acidified with $\mathrm{HCl}$ at different concentrations (1$6 \mathrm{~mol} \mathrm{~L}^{-1}$ ) were used. The $\mathrm{HCl}$ concentration in the A solution changed within $0-10 \mathrm{~mol} \mathrm{~L}^{-1}$. Taking into account the $\mathrm{HCl}$ concentration ranges in the $\mathrm{S}$ and A solutions as well as their flow rates, the actual $\mathrm{HCl}$ concentration available for the $\mathrm{HG}$ reaction varied between 0.6 and $7.6 \mathrm{~mol} \mathrm{~L}^{-1}$. It was established that above $3 \mathrm{~mol} \mathrm{~L}^{-1} \mathrm{HCl}$ in the $\mathrm{S}$ solution and independent of the $\mathrm{HCl}$ concentration in the A solution, the As responses coming from As(III), As(v) and MMA were improved, i.e. reached maxima that were close to those obtained when the $S$ solutions not acidified with $\mathrm{HCl}$ were used. At higher $\mathrm{HCl}$ concentrations, i.e. $>3 \mathrm{~mol} \mathrm{~L}^{-1}(\mathrm{~S})$ and $>8 \mathrm{~mol} \mathrm{~L}^{-1}(\mathrm{~A})$, DMA gave no response. A decrease in the signal for DMA under strong acidic HG reaction conditions was reported by other researchers. ${ }^{\mathbf{1 3 , 1 4 , 2 0 , 2 6 , 2 7 , 2 9}}$ Nevertheless, such a gradual decrease of the signal for MMA was also observed in previous studies. ${ }^{\mathbf{1 3 , 1 4 , 2 0 , 2 9}}$ These HG reaction conditions, although not applicable for DMA, could be however attractive in non-chromatographic As speciation. The response profiles obtained for all four As species using the S solutions prepared in $3 \mathrm{~mol} \mathrm{~L}^{-1} \mathrm{HCl}$ are demonstrated in Fig. $1 \mathrm{~b}$.

Efficient generation of As hydrides in the reaction with $\mathrm{CH}_{3} \mathrm{COOH}$ (Fig. 2) could be observed for As(III), DMA and MMA. The responses for $\mathrm{As}(\mathrm{v})$ in the entire studied $\mathrm{CH}_{3} \mathrm{COOH}$ concentration range were suppressed. These results are in agreement with those reported by other researchers. ${ }^{19,27}$ It was concluded that $0.5 \mathrm{~mol} \mathrm{~L}^{-1} \mathrm{CH}_{3} \mathrm{COOH}$ used for the $\mathrm{HG}$ reaction was effective for equalizing the responses of $\mathrm{As}(\mathrm{III})$ and DMA. In contrast, it was not sufficient for As(v) and MMA at all. MMA was converted to its hydride at concentrations of $2 \mathrm{~mol} \mathrm{~L}^{-1}$ and higher. Considering the $\mathrm{CH}_{3} \mathrm{COOH}$ concentration in the $\mathrm{A}$ solution and the flow rates of the $\mathrm{S}$ and $\mathrm{A}$ solutions, similar results were obtained when the $\mathrm{S}$ solutions were acidified with

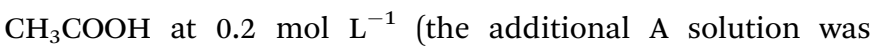
excluded). Furthermore, the influence of the $\mathrm{CH}_{3} \mathrm{COOH} / \mathrm{CH}_{3}$ COONa buffering reaction medium (acetate buffer) at $\mathrm{pH} 4.5$ on the responses of the As species was also checked. As shown in Fig. 2, the use of acetate buffer led to the same results for the As signals as that obtained in the presence of a low concentration of $\mathrm{CH}_{3} \mathrm{COOH}\left(0.2 \mathrm{~mol} \mathrm{~L}^{-1}\right.$ in the $\mathrm{S}$ solution). However, it was found that the acetate buffer concentration affected the generation of hydrides from As(III) and DMA. The same responses for both species were obtained only at the lower concentration range $\left(0.2-0.5 \mathrm{~mol} \mathrm{~L}^{-1}\right)$. Nevertheless, using the $0.2 \mathrm{~mol} \mathrm{~L}^{-1}$ buffer very weak signals for MMA were measured (i.e. $\sim 3.5 \%$ of the signals recorded for As(III) and DMA). Above this concentration, the measurable signals for MMA were not acquired at all. The signals for As(v) were always suppressed and not acquired.

In the case of $\mathrm{C}_{6} \mathrm{H}_{8} \mathrm{O}_{7}$, dependence of the signals for As(III) and DMA on their concentrations corresponded to those observed in the presence of $\mathrm{HCl}$, but as expected, the maxima of the As signals were shifted toward a lower $\mathrm{C}_{6} \mathrm{H}_{8} \mathrm{O}_{7}$ concentration $\left(0.1 \mathrm{~mol} \mathrm{~L}^{-1}\right)$. On the other hand, the response profiles found for $\mathrm{As}(\mathrm{v})$ and MMA were very similar to those obtained when $\mathrm{CH}_{3} \mathrm{COOH}$ was used for the $\mathrm{HG}$ reaction. Similar to $\mathrm{CH}_{3} \mathrm{COOH}$, low concentrations of $\mathrm{C}_{6} \mathrm{H}_{8} \mathrm{O}_{7}\left(<0.1 \mathrm{~mol} \mathrm{~L}^{-1}\right)$ ensured generation of arsines only for the As(III) and DMA species, but in contrast, equal signals were not obtained. HG of As carried out at adjusted $\mathrm{pH}$ (5.2) from the S solution prepared in $0.1 \mathrm{~mol} \mathrm{~L}^{-1}$ citrate buffer was additionally checked. Surprisingly, the results were different from those obtained when $\mathrm{C}_{6} \mathrm{H}_{8} \mathrm{O}_{7}$ was used. Accordingly, when the $\mathrm{HG}$ reaction was performed in the $\mathrm{NaBH}_{4}$-citric acid buffering mixture, only the As response of As(III) was not changed. The responses of the remaining species were negligible. Similar behavior was also observed by Karadjova et al. $^{28}$

3.2.2 Effect of $\mathrm{NaBH}_{4}$. The effect of various concentrations of $\mathrm{HCl}$ (1-10 mol L ${ }^{-1}$ ) and $\mathrm{NaBH}_{4}(0.1-1.0 \%)$ in the A and $\mathrm{R}$ solutions, respectively, on the responses of As(III), As(v), DMA and MMA coming from the simple (not acidified with $\mathrm{HCl}$ ) S solutions was studied. Higher than $1.0 \% \mathrm{NaBH}_{4}$ concentrations were avoided due to excessive $\mathrm{H}_{2}$ formation and plasma instability. It was observed that As(III) was easily converted into $\mathrm{AsH}_{3}$ already at the lowest $\mathrm{HCl}$ and $\mathrm{NaBH}_{4}$ concentrations, while its signal increased with the $\mathrm{HCl}$ and $\mathrm{NaBH}_{4}$ concentrations in both solutions. In contrast, generation of the As hydrides from DMA was effective only in the presence of the lowest $\mathrm{HCl}$ concentration and $\mathrm{NaBH}_{4}>0.3 \%$. The signal for DMA sharply decreased as the $\mathrm{HCl}$ concentration increased, however, the negative influence of more concentrated $\mathrm{HCl}$ in the case of DMA could be minimized by increasing the $\mathrm{NaBH}_{4}$ concentration. In the case of $\mathrm{As}(\mathrm{v})$ and MMA, higher concentrations of both $\mathrm{HCl}$ $\left(>6\right.$ mol L ${ }^{-1}$ ) and $\mathrm{NaBH}_{4}(>0.75 \%)$ were required to get their measurable signals, nevertheless, as compared to the responses of As(III), they were always up to 4-fold lower. Accordingly, the $\mathrm{NaBH}_{4}-\mathrm{HCl}$ reaction conditions that yielded the same As responses for all four species could not be easily predicted and evaluated. It is worth mentioning that only As(III) gave measurable and reproducible signals independent of the $\mathrm{NaBH}_{4}$ and $\mathrm{HCl}$ concentrations. Moreover, the behavior of As(III) in the $\mathrm{NaBH}_{4}-\mathrm{HCl}$ reaction medium was close to that observed using the $\mathrm{NaBH}_{4}$-citrate buffering reaction medium.

Hence, the obtained results from this experiment in addition to those carried out with citrate buffer were continued to evaluate the HG reaction conditions that would be applicable for selective determinations of the As species. In further experiments, corresponding arsines were generated at constant acidity and variable $\mathrm{NaBH}_{4}$ concentrations (from 0.01 to $1.0 \%$ ). The responses of As(III), As(v), DMA and MMA recorded under the selected reaction conditions are presented in Fig. 3.

At first, the effect of the $\mathrm{HCl}$ medium was examined. To make use of the negative behavior of $\mathrm{HCl}$ towards DMA (see Fig. 1b), high $\mathrm{HCl}$ concentrations in the $\mathrm{S}\left(3 \mathrm{~mol} \mathrm{~L}^{-1}\right)$ and $\mathrm{A}\left(10 \mathrm{~mol} \mathrm{~L}^{-1}\right)$ solutions were applied. As can be seen (Fig. 3a), the relationships between responses of As(III), As(v) and MMA were similar. The signals related to As(v) and MMA significantly increased with higher $\mathrm{NaBH}_{4}$ concentrations and reached the maximal values at $1.0 \% \mathrm{NaBH}_{4}$. In contrast, independent of the $\mathrm{NaBH}_{4}$ concentration, generation of the hydrides from DMA was 

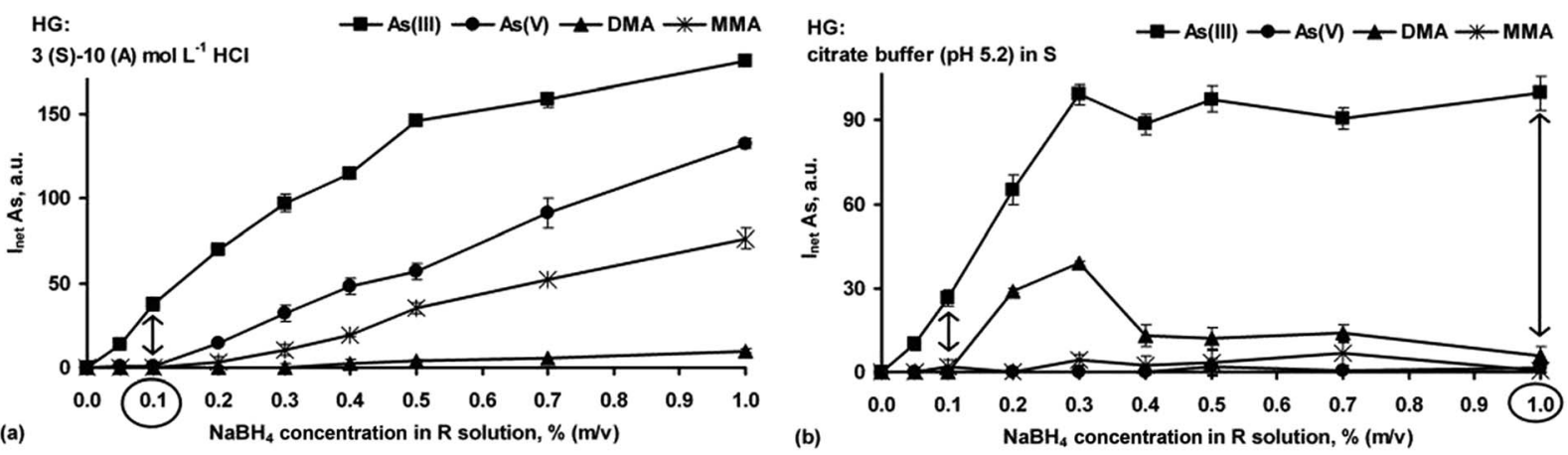

Fig. 3 Effect of the $\mathrm{NaBH}_{4}$ concentration on the measurements of As(III), As(v), DMA and MMA (20 ng g ${ }^{-1}$ each) by HG-ICP OES using HCl (a) or a citrate buffer ( $\mathrm{pH}$ 5.2) (b) for the HG reaction media. Inet: the average net intensity of the As line for $n=3$ measurements (S, A, R: sample, additional acid, reductant solutions).

irrelevant. In the region of lower $\mathrm{NaBH}_{4}$ concentrations, i.e. $\leq 0.1 \%$ only $\mathrm{As}$ (III) gave a measurable response. This is in agreement only with the results previously published by few researchers. ${ }^{13,14}$ Several other researchers obtained different results, ${ }^{26,41}$ but it must be noted that differences in the instrumental designs and HG procedures employed by others make such comparisons difficult.

Next, arsines were generated from the $\mathrm{S}$ solutions buffered at pH $5.2\left(0.1 \mathrm{~mol} \mathrm{~L}^{-1}\right.$ citrate buffer was used). It was established (Fig. 3b) that efficient generation of the As hydrides was achieved only for As(III) and DMA, but the $\mathrm{NaBH}_{4}$ concentration was critical. The signals for the As(v) and MMA forms were completely suppressed. Interestingly, using largely different $\mathrm{NaBH}_{4}$ concentrations $(0.1$ or $1.0 \%$ ) only As(III) could be determined. Nevertheless, $1.0 \% \mathrm{NaBH}_{4}$ was much better because the signal achieved for $\mathrm{As}(\mathrm{III})$ was 4 -fold higher than that achieved with $0.1 \% \mathrm{NaBH}_{4}$.

3.2.3 Effect of the pre-reducing agents. The results obtained so far showed that the i-As forms have different activities in the $\mathrm{HG}$ reaction with $\mathrm{NaBH}_{4}$ and the reaction rate is much slower for As(V) than for As(III). Every time the As signal coming from As(III) was higher (see Fig. 1a or Fig. 3a). Typically, when the total As concentrations are determined by HG, any As(v) species has to be initially pre-reduced to As(III). On the other hand, both organic As forms (o-As) are the V-valent state species, hence, it is expected that DMA and MMA can also be pre-reduced to their lower oxidation state forms. Suitability of the most commonly employed pre-reducing agents for As, i.e. $\mathrm{KI}^{10,11,13,14,17,18,26,28,30-35,38,40-42}$ and $\mathrm{TU},{ }^{13,16,36,37}$ alone or combined with $\mathrm{AA}$, as well as the less frequently chosen $\mathrm{LC}^{20,28,29,36,39}$ was tested for this aim. All the experiments were conducted at a fixed $\mathrm{NaBH}_{4}$ concentration $(1.0 \%)$ and variable $\mathrm{HCl}$ concentrations in the $\mathrm{S}$ and $\mathrm{A}$ solutions. The relationships of the responses of As(III), As(v), DMA and MMA with the $\mathrm{HCl}$ concentration were considered. It was due to the different behavior of the As species in the $\mathrm{HCl}$ medium (see Fig. 1) as well as the reaction requirements for the respective pre-reducing agents (in terms of the $\mathrm{HCl}$ concentration in the S solution). Single standard solutions of As(III), As(v), DMA or MMA, not subjected to pre-reduction, were taken as references.
The effect of the pre-reductants on the generation of the corresponding arsines and their role in the HG reaction for all As species are illustrated in Fig. 4-6 for KI, TU and LC, respectively.

The case of KI. In the case of KI, the mixture of this prereducing agent with AA (at $1: 4$ concentration ratio) was preferred to prevent formation of $\mathrm{I}_{2}$ by self-oxidation of the $\mathrm{I}^{-}$ ions in the $\mathrm{HCl}$ medium. A $0.5 \% \mathrm{KI}-2.0 \%$ AA mixture was chosen. It was also established that the $\mathrm{S}$ solution treated with $\mathrm{AA}+\mathrm{KI}$ (added separately, i.e. first AA then KI) before final acidification was more appropriate than when the already prepared mixture (KI-AA) was used.

As shown in Fig. 4a, generation of the As hydrides from DMA in the presence of KI-AA was not advantageous. Such behavior was not surprising because when KI was used, acidification of the $\mathrm{S}$ solution $\left(3 \mathrm{~mol} \mathrm{~L}^{-1} \mathrm{HCl}\right)$ was required. The relationship of the signal with acidity for DMA was the same as for the reference standard solution of DMA (see Fig. 1b). It may suggest that the responses of DMA after adding KI-AA depended more on the $\mathrm{HCl}$ concentration in the $\mathrm{S}$ and A solutions than on the KIAA itself. In contrast to DMA, the use of KI-AA was found to be effective for As(III), As(v) and MMA. Compared to their reference signals (see Fig. 1b), the As responses resulting from the presence of KI-AA were close to that of As(III). Successfully, with the highest $\mathrm{HCl}$ concentration in the A solution, complete prereduction was afforded. At this point, it appears that the KIAA mixture equalized the responses for the i-As and MMA forms (differences within the measurement error) as well as improved the signals during the measurements. Accordingly, a $\sim 11 \%$ increase in the signals for $\mathrm{As}(\mathrm{III}), \mathrm{As}(\mathrm{v})$ and MMA was obtained. It must be commented that KI-AA also provided practically the same responses for As(III), As(v) and MMA at lower $\mathrm{HCl}$ concentration in the A solution, i.e. $1 \mathrm{~mol} \mathrm{~L}^{-1} \mathrm{HCl}$. Nevertheless, the interference effect from DMA $(\sim 20 \%)$ was observed therein. Additionally, the positive effect of KI-AA was also verified to be valid when the arsines were generated at fixed acidity, i.e. 3 (S)-10 (A) $\mathrm{mol} \mathrm{L}^{-1} \mathrm{HCl}$, and varying $\mathrm{NaBH}_{4}$ concentrations, i.e. 0.01-1.0\%. As shown in Fig. 4b, complete conversion of $\mathrm{As}(\mathrm{V})$ and MMA to $\mathrm{As}(\mathrm{III})$ was assured and the resulting As responses were comparable to that obtained for the 

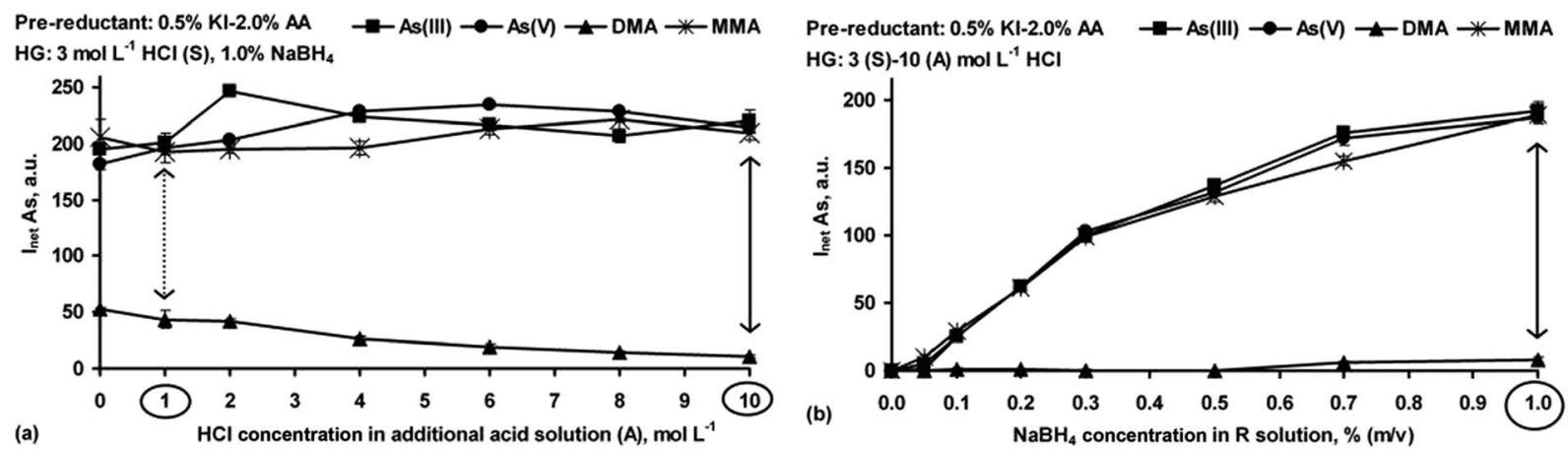

Fig. 4 Effect of the $\mathrm{HCl}$ concentration in the additional acid (A) solution (at fixed $1 \% \mathrm{NaBH}_{4}$ ) (a) and effect of the $\mathrm{NaBH}_{4}$ concentration in the $\mathrm{R}$ solution (at fixed acidity in the $\mathrm{S}$ and $\mathrm{A}$ solutions) (b) on the measurements of As(III), As(v), DMA and MMA (20 ng g ${ }^{-1}$ each) by HG-ICP OES using the $\mathrm{S}$ solutions containing $0.5 \% \mathrm{KI}-2.0 \% \mathrm{AA}$. Inet: the average net intensity of the As line for $n=3$ measurements (S, A, R: sample, additional acid, reductant solutions. AA: ascorbic acid).

reference standard solution of As(III) (see Fig. 3a). On the other hand, it was not sufficient for DMA. The positive behavior of the KI-AA mixture for As(v) and MMA in the present study agreed with that previously reported. ${ }^{26}$ Nevertheless, incomplete MMA conversion was also described. ${ }^{41}$

The case of TU. As reported previously for KI, the TU-AA mixture was favored due to the better solubility and stability of the $\mathrm{S}$ solutions containing TU-AA than TU alone. The mixture of TU-AA at a $1: 1$ concentration ratio gave the best results (complete pre-reduction was afforded) and S solution with $1 \%$ $\mathrm{KI}-1 \%$ AA was found to be optimal.

Analyzing the results (Fig. 5a), it can be concluded that generation of the As hydrides for As(III), As(V) and MMA was not negatively affected by the presence of TU-AA. The signal for DMA was reduced and this was attributed to the $\mathrm{HCl}$ concentration used. TU-AA provided complete pre-reduction of As(v) and MMA to As(III), independent of the $\mathrm{HCl}$ concentration in the A solution. Although the presence of $3 \mathrm{~mol} \mathrm{~L}^{-1} \mathrm{HCl}$ in the $\mathrm{S}$ solution led to suppression of the signal for DMA, TU-AA added to this solution had a positive effect on the generated DMA hydrides. It was observed that an increase in the $\mathrm{HCl}$ concentration in the A solution led to a significant growth of the response for DMA. At the highest, $10 \mathrm{~mol} \mathrm{~L}^{-1} \mathrm{HCl}$, its signal was $\sim 12$ times higher than that reached for the reference standard solution of DMA and $\sim 50 \%$ of the signals obtained for the remaining As species.

Deterioration of the DMA response in the presence of TU-AA could be achieved by lowering acidification of the $\mathrm{S}$ solution to $1 \mathrm{~mol} \mathrm{~L}^{-1} \mathrm{HCl}$. Under these conditions (Fig. 5b), corresponding signals coming from $\mathrm{As}(\mathrm{III}), \mathrm{As}(\mathrm{v})$ and MMA species were obtained, however, a higher concentration of $\mathrm{HCl}$ in the A solution ( $>6 \mathrm{~mol} \mathrm{~L}^{-1}$ ) had to be used for generation of their hydrides. Also, with lower acidification of the $\mathrm{S}$ solution, the responses for these As species were somewhat poorer (by 13-20\%). Although the signals for DMA considerably decreased (2.9-fold), with TUAA present in the S solution, no appropriate $\mathrm{HCl}$ concentration both in the S and A solutions was found to fully depress the DMA response.

The case of $L C$. LC can reduce As(v), DMA and MMA to the trivalent state already at low $\mathrm{HCl}$ concentration. ${ }^{20,28,29}$ Accordingly, the effect of the LC concentration in the S solution (0.25$1.0 \%)$ was initially studied. The experiments were performed at a fixed concentration of $\mathrm{HCl}$ and $\mathrm{NaBH}_{4}$ in the A and R solutions, i.e. $0.25 \mathrm{~mol} \mathrm{~L}^{-1}$ and $1.0 \%$, respectively. Simple (not acidified with $\mathrm{HCl}$ ) $\mathrm{S}$ solutions of each of the As species were analyzed first. It was found that the signals for all As species
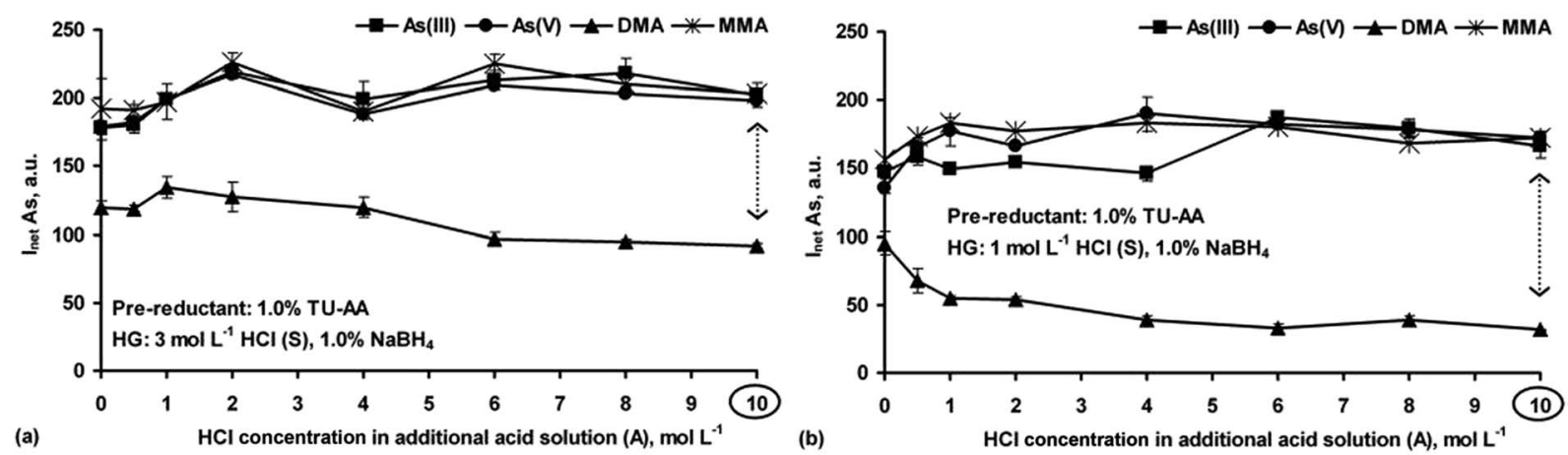

Fig. 5 Effect of the $\mathrm{HCl}$ concentration in the sample (S) and additional acid (A) solutions on the measurements of As(III), As(v), DMA and MMA (20 $\mathrm{ng} \mathrm{g}^{-1}$ each) by HG-ICP OES using $1.0 \% \mathrm{NaBH}_{4}$ and the $\mathrm{S}$ solutions containing $1.0 \% \mathrm{TU}-\mathrm{AA}$ and acidified to 3 (a) and 1 (b) mol $\mathrm{L}^{-1}$ of $\mathrm{HCl}$. Inet: the average net intensity of the As line for $n=3$ measurements (AA: ascorbic acid. TU: thiourea). 
increased up to $0.5 \% \mathrm{LC}$ and reached constant values up to $1.0 \%$ LC. Therefore, $0.5 \%$ LC was taken as optimal. The effect of the $\mathrm{HCl}$ concentration on $\mathrm{HG}$ of the As species in the presence of $0.5 \%$ LC was also examined using the S solutions acidified to 0.1-3 mol L $\mathrm{L}^{-1} \mathrm{HCl}$. The corresponding As hydrides were generated in the reaction between the acidified $\mathrm{S}$ solutions and the $1.0 \% \mathrm{NaBH}_{4}$ solution. Significant differences between the signals were obtained and this effect strongly depended on the $\mathrm{HCl}$ concentration in the S solution and the As form. However, the signal was lower at higher acidity versus lower acidity in the $\mathrm{S}$ solution.

Based on these observations, the effect of LC on HG of As as a function of the $\mathrm{HCl}$ concentration $\left(0.01-10 \mathrm{~mol} \mathrm{~L}^{-1}\right.$ in the A solution) was carefully studied. Simple S solutions containing $0.5 \%$ LC only (without additional $\mathrm{HCl}$ ) were used. The relationships between As(III), As(v), DMA and MMA responses and the $\mathrm{HCl}$ concentration are given in Fig. 6a. For a better overview, the region with the lower $\mathrm{HCl}$ concentrations $\left(<1 \mathrm{~mol} \mathrm{~L}^{-1}\right)$ is emphasized (Fig. 6b).

The observed changes in the signals versus the $\mathrm{HCl}$ concentration were extremely different to those obtained without LC in the S solutions (see Fig. 1a). Interestingly, the relationships between the signal and the $\mathrm{HCl}$ concentration for the i-As species were close to but different than those observed for the o-As species. Compared to the signals obtained without LC (see Fig. 1a), maximal signals for different As forms in the presence of LC related to the much lower and narrower acidity range $(0.2-$ $0.25 \mathrm{~mol} \mathrm{~L}^{-1} \mathrm{HCl}$ ). At a $\mathrm{HCl}$ concentration of $0.25 \mathrm{~mol} \mathrm{~L}^{-1}$ (Fig. 6b), the responses for As(III), As(v) and DMA were practically identical (differences within SDs) and higher by about $27 \%$ than the response coming from MMA. With further increase in the $\mathrm{HCl}$ concentration, the signals of all the As forms sharply decreased, reaching minima at $0.5-1 \mathrm{~mol} \mathrm{~L}^{-1} \mathrm{HCl}$ [for DMA and MMA] and 1-2 mol L ${ }^{-1} \mathrm{HCl}$ [for As(III) and As(v)] in the A solution. Passing the mentioned minima, the As signals of all the As species started to gradually rise with the increasing $\mathrm{HCl}$ concentration and reached maximal values at different concentrations. Interestingly, with $\mathrm{HCl}$ at 9 or $10 \mathrm{~mol} \mathrm{~L}^{-1}$ the same responses for all four As species were achieved, showing quantitative pre-reduction of As(v), DMA and MMA to As(III). The response profiles obtained here were close to those found by Carrero et al.,$^{20}$ but in contrast, it was possible in this work to get similar signals for $\mathrm{i}$-As and o-As at higher $\mathrm{HCl}$ concentrations $\left(>8 \mathrm{~mol} \mathrm{~L}^{-1}\right)$; those for $\mathrm{As}(\mathrm{III})$ and $\mathrm{As}(\mathrm{v})$, in the cited work, were $\sim 30 \%$ lower than those for DMA and MMA.

Additional experiments were carried out in which the $\mathrm{S}$ solutions with $0.5 \% \mathrm{LC}$ were acidified with $\mathrm{HCl}$ at different concentrations (1-4 $\mathrm{mol} \mathrm{L}^{-1}$ ) while the $\mathrm{HCl}$ concentration in the A solution changed within 6-10 $\mathrm{mol} \mathrm{L}^{-1}$. The obtained responses were compared with those achieved using the $\mathrm{S}$ solutions containing LC only. It was established that for As(III), As(v) and MMA, irrespective of the S solution acidity, the varying $\mathrm{HCl}$ concentration in the A solution did not change the signals for these species. On the other hand, the $\mathrm{HCl}$ concentration in the S solution led to improvement of the As signals coming from As(III), As(v) and MMA. In all cases, they were 20\% higher than that obtained for the respective reference standard solutions. However, when the $\mathrm{HCl}$ concentration increased above $3 \mathrm{~mol}$ $\mathrm{L}^{-1}$, poorer precision was noticed (RSDs $>8 \%$ ). In contrast, the presence of $\mathrm{HCl}$ in the $\mathrm{S}$ solutions up to $4 \mathrm{~mol} \mathrm{~L}^{-1}$ was responsible for deterioration of the As signals for DMA. Every time, its responses were two times lower than that recorded for the reference standard solution of DMA. The effect of the $\mathrm{HCl}$ concentration in the A solution was generally less critical. The changes in the DMA signals were minor $( \pm 5 \%)$.

In summary, the results showed an important role of the $\mathrm{HCl}$ concentration in the generation of the As hydrides for As(III), As(v), DMA and MMA in the presence of LC. Nevertheless, using $0.5 \% \mathrm{LC}$ and different $\mathrm{HCl}$ concentrations (both in the S and $\mathrm{A}$ solutions), several conditions applicable in As speciation could be selected (see e.g. in Fig. 6).

\subsection{Strategies for As determination and speciation by HG- ICP OES}

As presented above, the response of As achievable in the HG reaction strongly depends on the oxidation state (III/V), on the nature of the hydride-active As species (inorganic/organic) and experimental conditions. All the best variants that can be
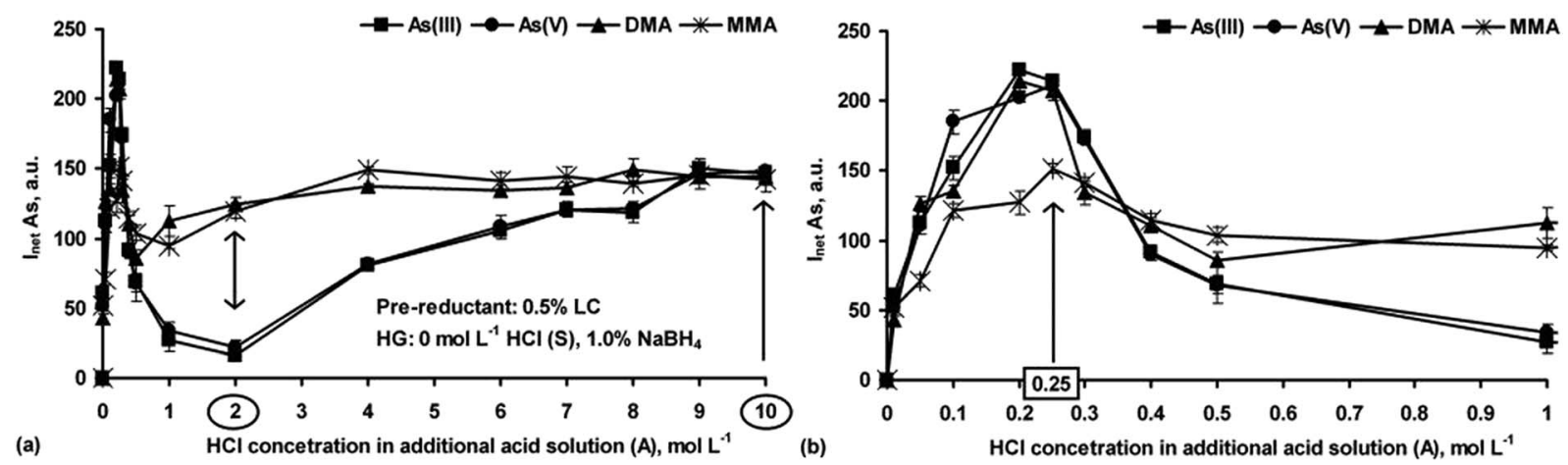

Fig. 6 Effect of the $\mathrm{HCl}$ concentration in the additional acid (A) solution on the measurements of As(III), As(V), DMA and MMA (20 ng g ${ }^{-1}$ each) by HG-ICP OES using 1.0\% $\mathrm{NaBH}_{4}$ and the simple $\mathrm{S}$ solutions containing $0.5 \% \mathrm{LC}$ (acidification with $\mathrm{HCl}$ was omitted). Acidification of the A solution with $\mathrm{HCl}$ within $0.01-10 \mathrm{~mol} \mathrm{~L}^{-1}(\mathrm{a})$ and within $0.01-1 \mathrm{~mol} \mathrm{~L}^{-1}(\mathrm{~b}) . I_{\text {net }}$ : average net intensity of the As line for $n=3$ measurements $(\mathrm{S}$ : sample solution. LC: L-cysteine). 
utilized for speciation of As by HG-ICP OES are listed in Table 2. The response of the As species is expressed as the relative intensity $\left(I_{\text {Rel }}\right)$, calculated as the ratio of the signal measured under the given conditions to the reference signal acquired under the optimum conditions for $\mathrm{AsH}_{3}$ generation in the HG system and the detection unit used in this work (see Section 3.1). Additionally, the compromised chemical conditions (prereduction and $\mathrm{HG}$ ) for determination of the total As concentration ( $\mathrm{t}$-As) are included in this table. Five favorable speciation procedures (SP1-SP5) are highlighted.

3.3.1 The case of As speciation. As shown in Table 2, useful procedures that lead to differences in the signals for all four As species were found. Accordingly, [As(III)] can be determined alone in the presence of the citrate buffer ( $\mathrm{pH} \mathrm{5.2)} \mathrm{and} \mathrm{1.0 \%}$ $\mathrm{NaBH}_{4}$ or under the HG reaction conditions related to the high $\mathrm{HCl}$ concentrations both in the $\mathrm{S}\left(3 \mathrm{~mol} \mathrm{~L}^{-1}\right)$ and $\mathrm{A}\left(10 \mathrm{~mol} \mathrm{~L}^{-1}\right)$ solutions and the low $\mathrm{NaBH}_{4}$ concentration (0.1\%). The concept of the HG reaction carried out at buffered $\mathrm{pH}$ was preferred (SP1). It resulted in more effective $\mathrm{AsH}_{3}$ generation since the signals originating from As(III) were 2.5-fold higher than those using the $\mathrm{NaBH}_{4}-\mathrm{HCl}$ mixture. It is crucial especially for low and very low concentrations of the analytes present in the $\mathrm{S}$ solutions.
The reaction medium of low concentrated $\mathrm{CH}_{3} \mathrm{COOH}$ $\left(0.2 \mathrm{~mol} \mathrm{~L}^{-1}\right.$ in the final reaction mixture) or in the presence of the acetate buffer $(\mathrm{pH} 4.5)$ and $1.0 \% \mathrm{NaBH}_{4}$ allowed for the determination of the sum of As(III) and DMA, i.e. [As(III) + DMA]. The differences between these procedures were rather not observed. The responses of As(III) and DMA were similar and their signals were very high, however, $\sim 20 \%$ lower than that associated with the signal for the reference standard solution of As(III). As discussed previously, the use of the buffered S solutions was preferred (SP2) due to better control of acidity of the reaction medium and complete suppression of the HG activity associated with the presence of $\mathrm{As}(\mathrm{v})$ and MMA.

The use of the $0.5 \% \mathrm{KI}-2.0 \%$ AA mixture in the $\mathrm{S}$ solution acidified to $3 \mathrm{~mol} \mathrm{~L}^{-1} \mathrm{HCl}$ and the $10 \mathrm{~mol} \mathrm{~L}^{-1} \mathrm{HCl}$ A solution for the $\mathrm{HG}$ reaction with $1.0 \% \mathrm{NaBH}_{4}$ (SP3) ensured determination of the sum of As(III), As(v) and MMA, i.e. [i-As + MMA], without contribution of DMA to the overall signal. The use of the TU-AA mixture was disregarded because of the interference effect from DMA $(\sim 16 \%)$ and lower responses for As(III), As(v) and MMA ( $\sim 15 \%$ decrease). It is worth noting that the KI-AA mixture was also found to be useful for leveling the signals during the measurements carried out under the optimum HG reaction conditions ( $\sim 15 \%$ increase).

Table 2 Optimum conditions for total As determination and its non-chromatographic speciation by HG-ICP-OES ${ }^{a}$

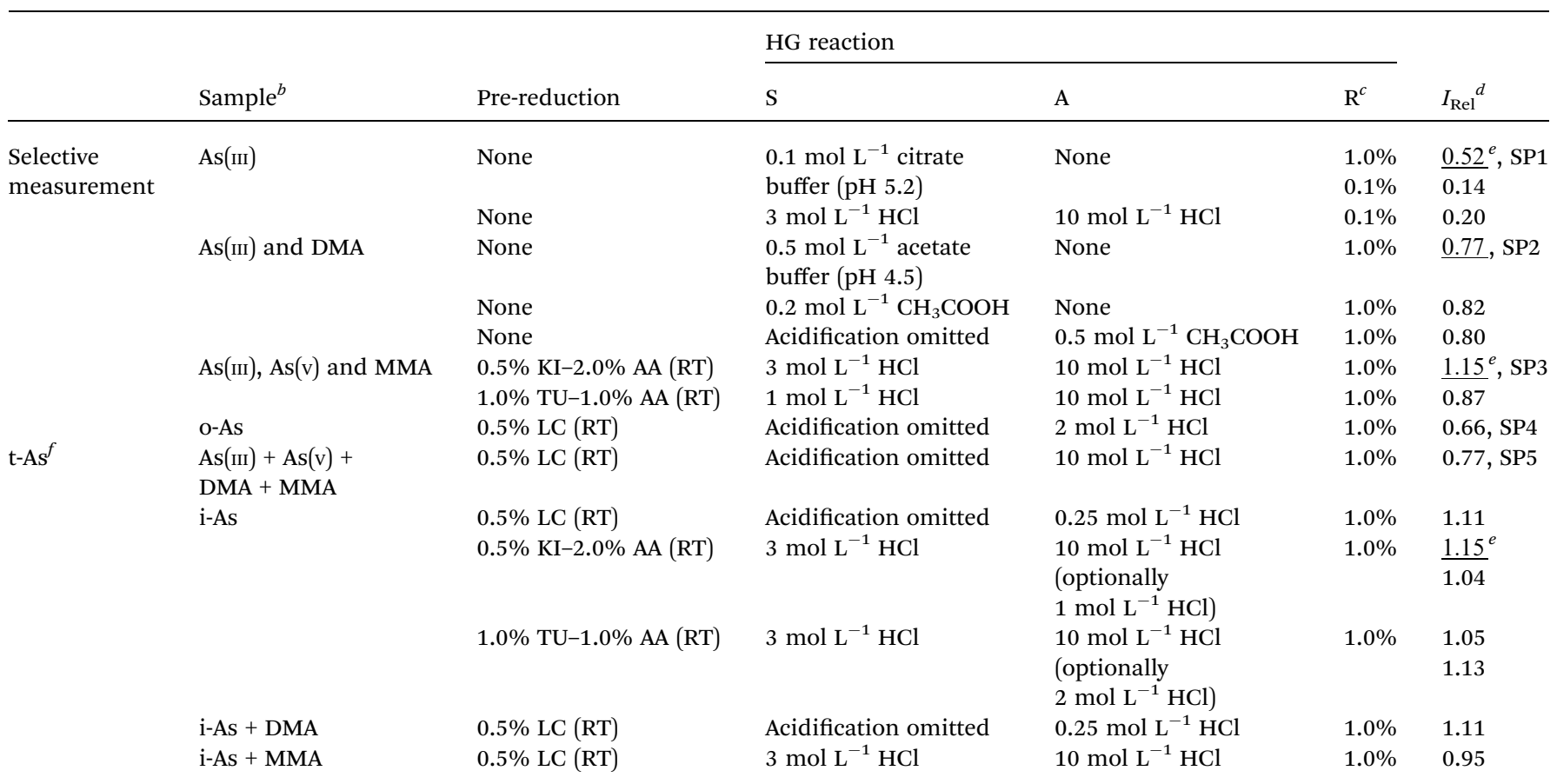

${ }^{a}$ S, A, R: sample, additional acid, reductant solutions. DMA: dimethylarsinate. MMA: monomethylarsonate. AA: ascorbic acid. LC: L-cysteine. TU: thiourea. RT: room temperature. t-As: the total content of the hydride-active As species. i-As: the inorganic tri- and pentavalent As species [As(III) and $\mathrm{As}(\mathrm{v})]$. o-As: the organic, i.e. methylated pentavalent As species (DMA and MMA). ${ }^{b}$ Standard solutions containing As(III), As(v), DMA and MMA were used. ${ }^{c} \mathrm{NaBH}_{4}$ in the $\mathrm{R}$ solution. ${ }^{d}$ Relative intensity calculated as the ratio of the measured intensity of the As analytical line under the given

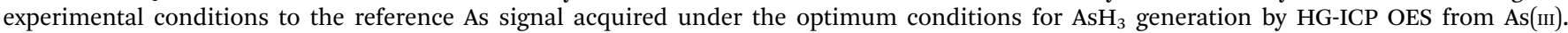
${ }^{e}$ Underlined $=$ favorable pre-reduction and/or HG reaction conditions; SP1-SP5 refer to the optimum speciation procedures (SPs) for speciesselective As determination under these favorable conditions. ${ }^{f}$ As As(III) for the tri- and pentavalent inorganic and organic arsenic species after pre-reduction. 
Interestingly, the sum of the o-As species, i.e. [DMA + MMA], could be selectively determined after pre-reduction of the simple (not acidified with $\mathrm{HCl}$ ) S solutions with $0.5 \% \mathrm{LC}$, followed by $\mathrm{HG}$ with $1.0 \% \mathrm{NaBH}_{4}$ in the $2 \mathrm{~mol} \mathrm{~L}^{-1} \mathrm{HCl}$ medium (SP4). The signals achieved for the S solutions pre-treated in this way were nearly $70 \%$ of that measured for As(III).

3.3.2 The case of t-As. In the selected procedures for the determination of $\mathrm{t}$-As, the composition of the $\mathrm{S}$ solution plays a significant role. For the standard solutions containing the i-As form only determination of t-As by $\mathrm{HG}$ seems to be the most effective in the presence of the high $\mathrm{HCl}$ concentration in the reaction mixture $\left(>5 \mathrm{~mol} \mathrm{~L}^{-1}\right)$ and pre-reduction using $0.5 \% \mathrm{KI}-$ $2.0 \%$ AA. The use of KI-AA seems to be more attractive than TUAA, because the maximal responses, additionally improved, can be obtained under the same HG reaction conditions. It must also be commented that for the case when the S solution did not contain any o-As forms, the $\mathrm{HCl}$ concentration in the A solution can be significantly reduced (to $1-2 \mathrm{~mol} \mathrm{~L}^{-1}$ ). Optionally, the $\mathrm{S}$ solution can also be treated with $0.5 \%$ LC, but in this case rigorous control of acidity for the $\mathrm{HG}$ reaction is required $\left(0.25 \mathrm{~mol} \mathrm{~L}^{-1} \mathrm{HCl}\right.$ in the A solution) and simple S solutions (not acidified with $\mathrm{HCl}$ ) are needed.

Similarly, in reference to the activity of the individual As species during $\mathrm{HG}$ in the presence of $0.5 \%$ LC and depending on the acidity conditions employed (either in the S or A solutions), determination of $\mathrm{t}$-As in the $\mathrm{S}$ solutions containing three As forms, i.e. i-As + DMA or i-As + MMA as well as all four As species, i.e. As(III) + As(v) + DMA + MMA, is possible. In the first case, however, absence of MMA (for i-As + DMA) or DMA (for i-As + MMA) in the $S$ solution must be considered to obtain reliable results. For example, for 0 (S)- 0.25 (A) $\mathrm{mol} \mathrm{L}^{-1} \mathrm{HCl}$ conditions for HG of i-As and DMA, the contribution of MMA to the overall signal is high $(\sim 73 \%)$. Similarly, the presence of DMA may affect quantification of the sum of i-As + MMA because under the optimum HG reaction conditions, i.e. 3 (S)-10 (A) $\mathrm{mol} \mathrm{L}^{-1}$ $\mathrm{HCl}$, the response of DMA reached nearly $50 \%$ of that achieved for other species. In the second case, determination of t-As is possible, regardless of the different As species present in the $\mathrm{S}$ solution. In this procedure (SP5), the simple S solution treated with $0.5 \%$ LC only and the high $\mathrm{HCl}$ concentration $\left(10 \mathrm{~mol} \mathrm{~L}^{-1}\right.$ $\mathrm{HCl}$ ) in the A solution for the $\mathrm{HG}$ reaction can be applied. This treatment assures identical responses of all four species but at the cost of lower HG efficiency by $24 \%$ for As(III).

\subsection{Non-chromatographic As speciation - speciation protocols}

Detection of the As species in one solution was investigated in order to examine the selectivity of the optimum speciation procedures (SP1-SP5). Both single standards (with each species at 10 and $20 \mathrm{ng} \mathrm{g}^{-1}$ ) and mixed standard solutions were analyzed. The concentrations of the species in the respective mixtures were the same that corresponded to 40 and $80 \mathrm{ng} \mathrm{g}^{-1}$ of total As, respectively. The obtained results are demonstrated in Fig. 7 and expressed as the relative intensity $\left(I_{\text {Rel }}\right)$, i.e. the ratio of the signal acquired for a given As species in the $S$

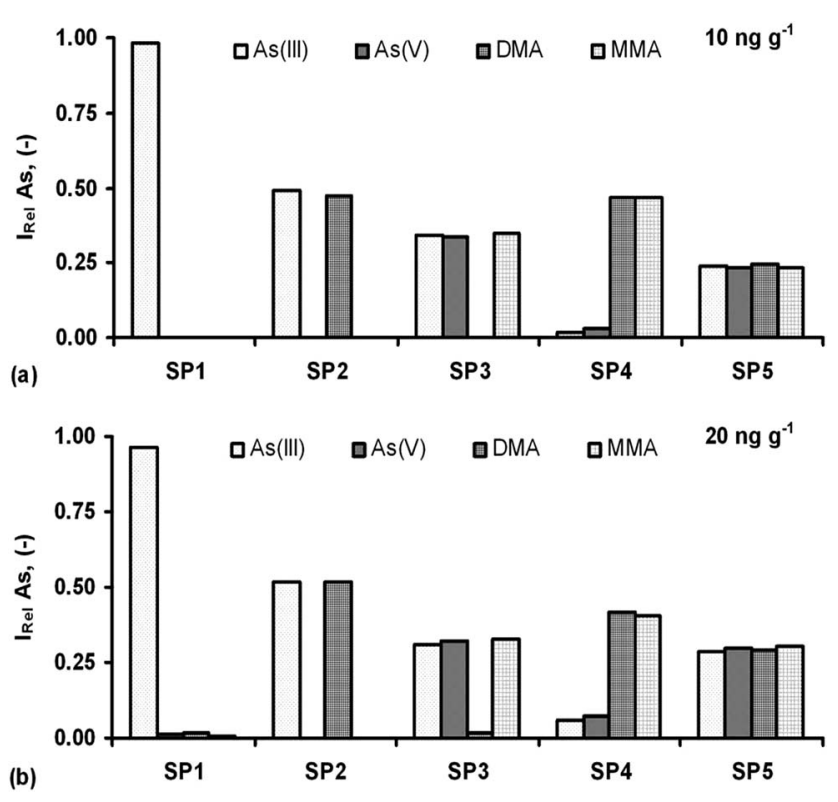

Fig. 7 Assessment of the optimum speciation procedures (SPs) for species-selective As determination by HG-ICP OES in the $S$ solutions containing 10 (a) and $20 \mathrm{ng} \mathrm{g}^{-1}$ (b) of As(III), As(v), DMA and MMA. I Rel: relative intensity calculated as the ratio of the $I_{\text {net }}$ acquired for a given As species in the $S$ solution without and with the remaining species under SP conditions. SP1: [As(III)]. SP2: [As(III) + DMA]. SP3: [As(III) + As(V) + MMA]. SP4 [DMA + MMA]. SP5: [As(III) + As(V) + DMA + MMA].

solution without and with the remaining species, depending on the SP used.

Any potential interferences were minor for the $S$ solution with the t-As content of $80 \mathrm{ng} \mathrm{g}^{-1}$ (Fig. 7b) or there were practically no interferences for the $\mathrm{S}$ solution with the t-As content of $40 \mathrm{ng} \mathrm{g}^{-1}$ (Fig. 7a). It leads to the conclusion that different As species can be determined in one solution by performing species-selective HG and ICP OES detection. Small potential interferences from i-As in the determination of o-As under SP4 were noted. In this approach, the signals for As(III) and As(v) reached maximally $13 \%$ of those for DMA and MMA, however, only for higher i-As concentrations in the $\mathrm{S}$ solution $\left(20 \mathrm{ng} \mathrm{g}^{-1}\right)$. At lower i-As concentrations (10 $\left.\mathrm{ng} \mathrm{g}^{-1}\right)$, only DMA and MMA gave measurable and reproducible responses. For As(III) and As(v), irreproducible responses, being close to the blank level, were obtained and hence, the potential interference effect from both i-As forms was below 5\%. These SPs also enabled the satisfactory repeatability of measurements (precision), usually within 1-6\%. The respective RSDs were between 4.9 and $6.5 \%$ (SP1), 1.6 and $3.8 \%$ (SP2), 1.9 and $4.6 \%$ (SP3), 3.3 and $4.7 \%$ (SP4) and 1.4 and $5.9 \%$ (SP5). Preliminary experiments have also been made to test the applicability of the HG-ICP OES method with the developed SP procedures. They were included in the speciation of As in natural drinking water, where the samples were spiked with four As species (10 and $20 \mathrm{ng} \mathrm{g}^{-1}$ ) and determined following the respective SP procedures. As a result, quantitative recoveries of the added As species were obtained, i.e. 97.2103.6\% [As(III)], 96.0-101.7\% [As(v)], 94.3-102.1\% (DMA) and 98.8-104.9\% (MMA), depending on their optimum conditions for the respective SP procedure used. 
Finally, based on the different reactivities of all four As species under SP1-SP5 conditions, the protocols for nonchromatographic speciation of As were proposed. By combining the responses obtained for these five protocols, speciation of hydride-active As species, i.e. As(III), As(v), DMA and MMA, was possible. In addition to individual speciation, the scenario to fractionate As was evaluated. In the case of fractionation analysis, differentiation between the As species having the same nature was achieved. Examples of variants for the measurements of two-, three- and four-species of As in one solution were evaluated and are detailed in Table 3.

Table 3 Non-chromatographic speciation protocols of As by HG-ICP OES ${ }^{a}$

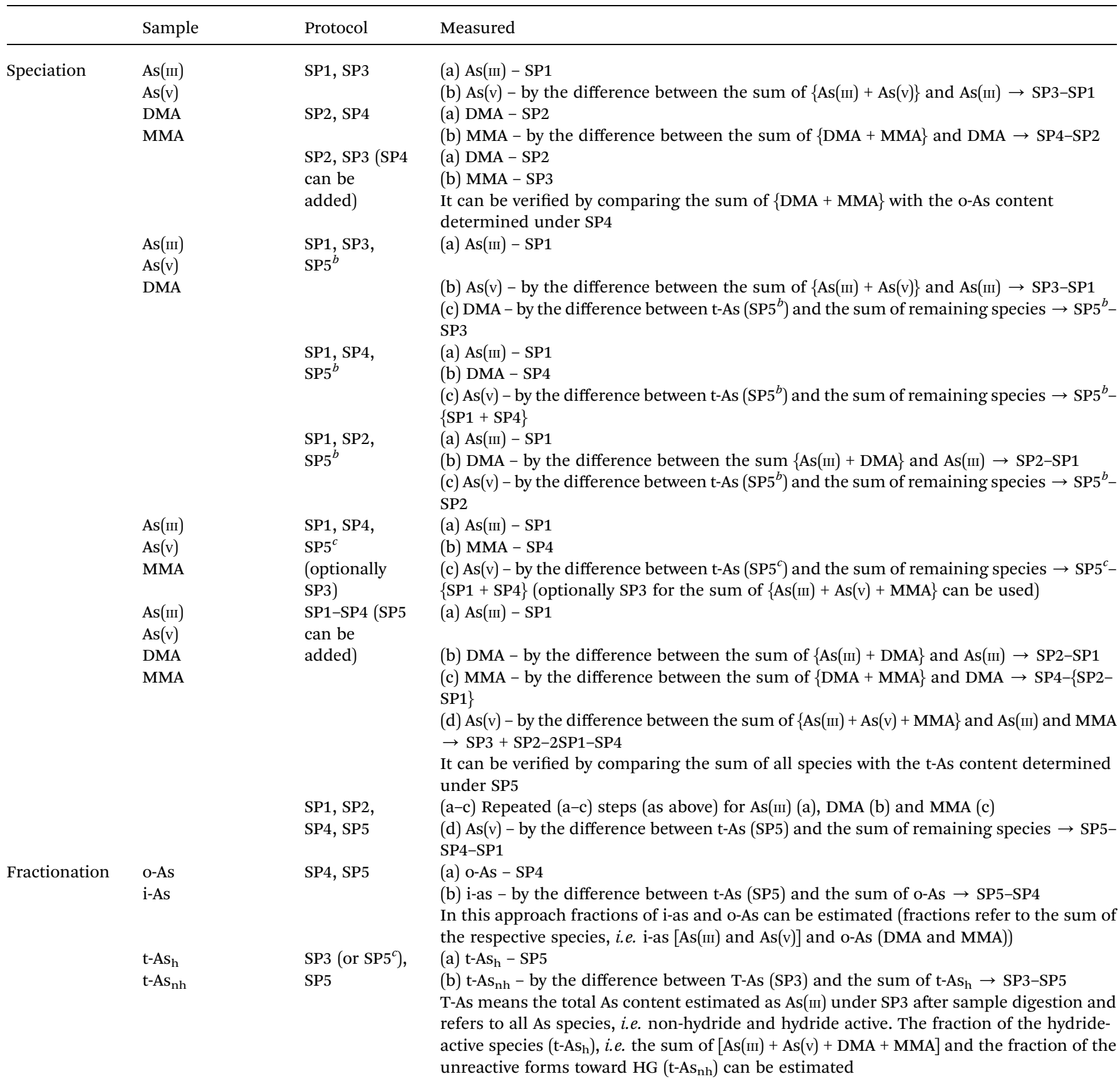

${ }^{a}$ SP1-SP5: the optimum speciation procedures for the As species. SP1: [As(III)], SP2: [As(III) + DMA], SP3: [As(III) + As(V) + MMA], SP4: [DMA + MMA], SP5: [As(III) + As(v) + DMA + MMA]. DMA: dimethylarsinate. MMA: monomethylarsonate. T-As: the total As content (hydride-active and non-hydrideactive forms). t-As: the total content of the hydride-active As species. i-As: the inorganic As species [As(III) and As(v)]. o-As: the organic, i.e. methylated pentavalent As species (DMA and MMA). $t-\mathrm{As}_{\mathrm{h}}$ : the fraction of the hydride-active As species [As(III) + As(v) + DMA + MMA].t-As $\mathrm{sh}_{\mathrm{nh}}$ : the fraction of the non-hydride active As species. ${ }^{b}$ As As(III) after pre-reduction with $0.5 \% \mathrm{LC}$ for the unacidified sample solution. $0.25 \mathrm{~mol} \mathrm{~L}^{-1} \mathrm{HCl}_{(\mathrm{A})}$ and $1 \% \mathrm{NaBH}_{4}$ (R) used for HG. ${ }^{c}$ As As(III) after pre-reduction with $0.5 \% \mathrm{LC}$ for the sample solution acidified to $3 \mathrm{~mol} \mathrm{~L}^{-1} \mathrm{HCl}^{10} \mathrm{~mol} \mathrm{~L}^{-1} \mathrm{HCl}(\mathrm{A})$ and $1 \% \mathrm{NaBH}$ (R) used for HG. 


\section{Conclusions}

Determination of As by HG-ICP OES through the reaction with $\mathrm{NaBH}_{4}$ in the acidic medium from sample solutions containing various, differing by the oxidation state (III/V) and nature (inorganic/organic), species of this element is not an easy task. Four major As species, i.e. As(III), As(v), DMA and MMA, react with $\mathrm{NaBH}_{4}$ in extremely different ways, depending on the reductant concentration, the reaction medium used for generation of the As hydrides (related to the type of acid and its acidity) and finally, the kind of pre-reducing agent employed in the pre-reduction step. The compromised reaction conditions, under which the same response for all four As species can be obtained, have to be found in order to obtain reliable results for determination of the total concentration of As.

Otherwise, careful control of the reaction medium, the concentration of $\mathrm{NaBH}_{4}$ and the pre-reducing agent used results (as demonstrated in this study) in selective generation of the hydrides of different As species directly by HG-ICP OES and enables speciation of this element. By combining the responses obtained under different pre-reduction and HG reaction conditions, several protocols for speciation of all four As species in one solution were proposed. Taking into account the measurements of total i-As alone for risk-assessment purposes, the interference effect arising from o-As in HG cannot be ignored. However, it was possible to establish adequate prereduction and $\mathrm{HG}$ reaction conditions to determine i-As in the presence of o-As without prior separation.

Nowadays, it is well accepted that the combination of HPLC with ICP MS, although very expensive, is the best tool for element speciation because it provides a complete and sophisticated picture of the species eluted from one injection of a sample, moreover, quantified at a (ultra)trace level. On the other hand, in some cases, like for As, it is sufficient to determine e.g. only the most toxic species [As(III,V)] or the group of species of this element (i-As, o-As) as a screening parameter to obtain important information for environmental or food purposes. In this sense, nonchromatographic techniques based on a simple instrumentation (with atomic spectrometric detectors available in most laboratories) can be alternatively used in the speciation studies. They offer shorter analysis time, lower costs and comparable or even better sensitivity (related to the possible species separation improving their pre-concentration) than that provided by the traditional chromatographic approaches. In reference to this, the selective procedures evaluated here for the determination of $\mathrm{As}(\mathrm{III}), \mathrm{As}(\mathrm{v})$, DMA and MMA clearly show the potential of the HG technique coupled to ICP OES for the non-chromatographic As speciation. Although the results of this study refer to simple sample solutions, i.e. standards and natural drinking water, they are important, because they indicate the possibility to effectively speciate and fractionate As obviating in this way chromatographic separation.

\section{Acknowledgements}

This study was funded by a statutory activity subsidy from the Polish Ministry of Science and Higher Education for the Faculty of Chemistry, Wroclaw University of Science and Technology.

\section{References}

1 S. Caroli, F. L. Torre, F. Petrucci and N. Violante, Arsenic speciation and Health Aspects, in Element Speciation in Bioinorganic Chemistry, ed. S. Caroli, John Wiley and Sons, New York, 1996, pp. 445-463.

2 S. Chen, Q. Guo and L. Liu, Food Anal. Methods, 2017, 10, 740-748.

3 T. Narukawa, A. Hioki and K. Chiba, J. Agric. Food Chem., 2012, 60, 1122-1127.

4 B. Sadee, M. E. Foulkes and S. J. Hill, J. Anal. At. Spectrom., 2015, 30, 102-118.

5 L. Jorhem, C. Astrand, B. Sundstrom, M. Baxter, P. Stokes, J. Lewis and K. Petersson Grawe, Food Addit. Contam., Part A, 2008, 25, 284-292.

6 M. Fontcuberta, J. Calderon, J. R. Villalbí, F. Centrich, S. Portana, A. Espelt, J. Duran and M. Nebot, J. Agric. Food Chem., 2011, 59, 10013-10022.

7 I. N. Pasias, N. S. Thomaidi and E. A. Piperaki, Microchem. J., 2013, 108, 1-6.

8 T. Ahmadi-Jouibari and N. Fattahi, Food Addit. Contam., Part A, 2015, 32, 1140-1147.

9 W. H. Lamont, J. Food Compos. Anal., 2003, 16, 687-695.

10 G. Chen and T. Chen, Talanta, 2014, 119, 202-206.

11 R. R. Rasmussen, Y. Qian and J. J. Sloth, Anal. Bioanal. Chem., 2013, 405, 7851-7857.

12 Y. Huang, J. Shan, B. Fan, Y. He, S. Xia, Y. Sun, J. Lu, M. Wang and F. Wang, Anal. Methods, 2015, 7, 8896-8900.

13 S. Musil, Á. H. Petursdottir, A. Raab, H. Gunnlaugsdottir, E. Krupp and J. Feldmann, Anal. Chem., 2014, 86, 993-999.

14 K. Tasev, I. Karadjova and T. Stafilov, Microchim. Acta, 2005, 149, 55-60.

15 G. Luo, Anal. Lett., 2012, 45, 2493-2507.

16 P. Pohl, TrAC, Trends Anal. Chem., 2004, 23, 87-101.

17 M. Welna, Aust. J. Chem., 2015, 68, 441-446.

18 J. R. Behari and R. Prakash, Chemosphere, 2006, 63, 17-21.

19 K. Marschner, S. Musil and J. Dedina, Anal. Chem., 2016, 88, 6366-6373.

20 P. Carrero, A. Malave, J. L. Burguera, M. Burguera and C. Rondon, Anal. Chim. Acta, 2001, 438, 195-204.

21 A. N. Anthemidis, G. A. Zachariadis and J. A. Stratis, Anal. Chim. Acta, 2005, 547, 237-242.

22 P. Liang and A. Li, Fresenius. J. Anal. Chem., 2000, 368, 418420.

23 P. Cicero do Nascimento, D. Bohrer, E. Becker and L. Machado de Carvalho, J. Non-Cryst. Solids, 2005, 351, 1312-1316.

24 A. Gonzalvez, M. L. Cervera, S. Armenta and M. de la Guardia, Anal. Chim. Acta, 2009, 636, 129-157.

25 M. A. Vieira, P. Grinberg, C. R. R. Bobeda, M. N. M. Reyes and R. C. Campos, Spectrochim. Acta, Part B, 2009, 64, 459-476.

26 J. Majda Bundaleska, T. Stafilov and S. Arpadjan, Int. J. Environ. Anal. Chem., 2005, 85, 199-207.

27 Y. Y. Cabon and N. Cabon, Anal. Chim. Acta, 2000, 418, 19-31.

28 I. B. Karadjova, L. Lampugnani, M. Onor, A. D. '. Ulivo and D. L. Tsalev, Spectrochim. Acta, Part B, 2005, 60, 816-823. 
29 A. Shraim, B. Chiswell and H. Olszowy, Talanta, 1999, 50, 1109-1127.

30 M. N. Matos Reyes, M. L. Cervera, R. C. Campos and M. de la Guardia, Spectrochim. Acta, Part B, 2007, 62, 1078-1082.

31 P. Cava-Montesinos, K. Nilles, M. L. Cervera and M. de la Guardia, Talanta, 2005, 66, 895-901.

32 P. K. Petrov, J. Majda Serafimovska, S. Arpadjan, D. L. Tsalev and T. Stafilov, Cent. Eur. J. Chem., 2008, 6, 216-221.

33 S. M. Macedo, D. C. dos Santos, R. M. de Jesus, G. O. da Rocha, S. L. C. Ferreira and J. B. de Andrade, Microchem. J., 2010, 96, 46-49.

34 S. M. Macedo, R. M. de Jesus, K. S. Garcia, V. Hatje, A. F. d. S. Queiroz and S. L. C. Ferreira, Talanta, 2009, 80, 974-979.

35 S. Maity, S. Chakravarty, P. Thakur, K. K. Gupta, S. Bhattacharjee and B. C. Roy, Chemosphere, 2004, 54, 1199-1206.
36 A. Maratta, L. Dante Martinez and P. Pacheco, Microchem. J., 2016, 127, 199-205.

37 L. Cai, C. Xu, M. Zhong, Y. Wu and S. Zheng, Asian J. Chem., 2013, 25, 8169-8172.

38 M. E. Sigrist and H. R. Beldomenico, Spectrochim. Acta, Part $B, 2004$, 59, 1041-1045.

39 J. Muller, Fresenius. J. Anal. Chem., 1999, 363, 572-576.

40 A. Caballo-Lopez and M. D. Luque de Castro, J. Anal. At. Spectrom., 2002, 17, 1363-1367.

41 C. Cerveira, D. Pozebon, D. Pompeu de Moraes and J. Camila Silva de Fraga, Anal. Methods, 2015, 7, 4528-4534.

42 T. Deng and M. Liao, Spectrosc. Lett., 2005, 38, 109-119.

43 M. Welna, J. Lasowska and W. Zyrnicki, J. Braz. Chem. Soc., 2011, 22, 1164-1167. 